Wong Joshua (Orcid ID: 0000-0002-9824-8746)

Hamblin Peter (Orcid ID: 0000-0002-6280-865X)

2

BRIEF COMMUNICATIONS

\title{
Case Series: Lead Poisoning Associated with Illicit Opium Use
}

\author{
Joshua Wong ${ }^{1}$, Elyssia Bourke ${ }^{2}$, Vanessa Roberts ${ }^{3}$, Seok Ming Lim ${ }^{1}$, Douglas Johnson \\ ${ }^{1}$ Peter Shane Hamblin ${ }^{3}$, Harin Karunajeewa ${ }^{3}$ and Shaun Greene ${ }^{2}$ \\ ${ }^{1}$ The Royal Melbourne Hospital, ${ }^{2}$ Austin Health and ${ }^{3}$ Western Health, Victoria, Australia
}

Authors Details:

\begin{tabular}{|c|c|c|c|}
\hline Author & Position & Affiliation & Contribution \\
\hline Dr Joshua Wong & $\begin{array}{c}\text { General Medical } \\
\text { Registrar }\end{array}$ & $\begin{array}{l}\text { The Royal } \\
\text { Melbourne } \\
\text { Hospital }\end{array}$ & $\begin{array}{l}\text { Clinician taking care of } \\
\text { x2 of the cases in the } \\
\text { case series and co- } \\
\text { writer of the } \\
\text { manuscript }\end{array}$ \\
\hline Dr Elyssia Bourke & Emergency Registrar & Austin Health & $\begin{array}{l}\text { Clinician taking care of } \\
\text { x1 of the cases in the } \\
\text { case series and co- } \\
\text { writer of the } \\
\text { manuscript }\end{array}$ \\
\hline Dr Vanessa Roberts & Surgical Resident & Western Health & $\begin{array}{c}\text { Clinician taking care of } \\
\text { x1 of the cases, } \\
\text { contributed case to } \\
\text { manuscript }\end{array}$ \\
\hline Dr Seok Ming Lim & $\begin{array}{c}\text { Geriatrician } \\
\text { Medical Unit } 2 \\
\text { Consultant } \\
\text { Head of the Hospital in } \\
\text { The Home Unit }\end{array}$ & $\begin{array}{l}\text { The Royal } \\
\text { Melbourne } \\
\text { Hospital }\end{array}$ & $\begin{array}{l}\text { Consultant taking care } \\
\text { of x } 1 \text { of the cases and } \\
\text { editor of entire } \\
\text { manuscript }\end{array}$ \\
\hline $\begin{array}{c}\text { A/Prof Douglas } \\
\text { Johnson }\end{array}$ & $\begin{array}{c}\text { Infectious Diseases } \\
\text { Physician }\end{array}$ & $\begin{array}{l}\text { The Royal } \\
\text { Melbourne }\end{array}$ & $\begin{array}{c}\text { Editor of entire } \\
\text { manuscript }\end{array}$ \\
\hline
\end{tabular}

This is the author manuscript accepted for publication and has undergone full peer review but has not been through the copyediting, typesetting, pagination and proofreading process, which may lead to differences between this version and the Version of Record. Please cite this article as doi: $10.1111 /$ imj.14729

This article is protected by copyright. All rights reserved. 


\begin{tabular}{|c|c|c|c|}
\hline & $\begin{array}{l}\text { General Medical Unit } \\
\text { Consultant } \\
\text { Head of General } \\
\text { Medical Department }\end{array}$ & Hospital & \\
\hline $\begin{array}{c}\text { A/Prof Peter Shane } \\
\text { Hamblin }\end{array}$ & Endocrinologist & Western Health & $\begin{array}{l}\text { Supervisor for case } \\
\text { submitted by Western } \\
\text { Health, aided in } \\
\text { editing of the } \\
\text { submitted case to the } \\
\text { case series }\end{array}$ \\
\hline $\begin{array}{l}\text { A/Prof Harin } \\
\text { Karunajeewa }\end{array}$ & $\begin{array}{l}\text { General Medicine } \\
\text { Consultant } \\
\text { Director Of Clinical } \\
\text { Research }\end{array}$ & Western Health & $\begin{array}{c}\text { Consultant taking care } \\
\text { of } \times 1 \text { of the cases }\end{array}$ \\
\hline Dr Shaun Greene & $\begin{array}{l}\text { Medical Toxicologist } \\
\text { Emergency Physician } \\
\text { Medical Director of } \\
\text { the Victorian Poisons } \\
\text { Information Centre }\end{array}$ & Austin Health & $\begin{array}{c}\text { Overall supervisor for } \\
\text { the case series and } \\
\text { editor of the entire } \\
\text { manuscript }\end{array}$ \\
\hline
\end{tabular}

\section{Correspondence:}

Joshua Wong, General Medical Office, The Royal Melbourne Hospital, Parkville, VIC, 3050, Australia. Mobile+61 433325 100. Email: joshua.wong@mh.org.au,

\section{Acknowledgements:}

Dr Ashish Kumar Panigrahi (Clinical Haematology Registrar, Peter MacCallum Cancer Centre) for providing the blood films included in Figure 1.

\section{Word Count:}

Abstract -85 words

Main Text - 1713 words 


\begin{abstract}
:
Lead poisoning is an uncommon and challenging diagnosis to make. In 2018, The Victorian Department of Health issued a health warning following four cases of lead poisoning associated with illicit opium use in Melbourne, Australia. We present these cases to highlight clinical features and the relevant investigations leading to diagnosis. All cases occurred in recent immigrants to Australia, who had access to non-traditional sources of opioids. Health care professionals should consider lead poisoning in patients with appropriate symptoms and a history of illicit opium use.
\end{abstract}

\title{
Key words:
}

Lead Poisoning, Opium, Opioids, Iran, Australia

In Australia, lead poisoning is uncommon. Improved occupational practices and restriction of lead content in paint and fuel have greatly reduced human lead exposure within the Australian community. A recent cluster of lead poisoning cases in Victoria serve to highlight alternative sources of lead exposure and remind clinicians of the clinical findings and investigations that can aid in diagnosing this rare but significant condition.

We report a case series of four adult males of Middle Eastern background who present to Victorian hospitals with lead poisoning stemming from daily use of recreational opium, allegedly sourced from Iran. All presented multiple times to health service providers with subacute (2-4 weeks) gastrointestinal symptoms of abdominal pain, constipation, vomiting and lethargy, with subsequent investigations showing microcytic hypochromic anaemia and basophilic stippling on blood film. Elevated serum lead levels ranged from $4.77 \mathrm{umol} / \mathrm{L}$ to 7.75umol/L (normal range $<0.24 \mathrm{umol} / \mathrm{L}$ ). All patients recovered symptomatically with dimercaptosuccinic acid (DMSA) chelation therapy in conjunction with treatment for opioid 
withdrawal. Post chelation, lead levels ranged from $2.65 \mathrm{umol} / \mathrm{L}$ to $3.32 \mathrm{umol} / \mathrm{L}$. Two out of four patients did not attend follow-up care.

The cases are as follows:

1. A 32-year-old male, recently emigrated from the Islamic Republic of Iran, presented multiple times to the Emergency Department (ED) over two weeks with recurrent abdominal pain, lethargy, constipation and vomiting. Initial investigations were nondiagnostic. Full Blood Examination (FBE) demonstrated microcytic hypochromic anaemia (haemoglobin $(\mathrm{Hb}$ ) 98g/L). Iron studies were normal. Liver Function Tests (LFTs) were mildly deranged (ALT 105U/L, AST 59U/L, GGT 46U/L, Bilirubin 25umol/L). Abdominal plain film revealed faecal loading. Follow-up blood film exhibited basophilic stippling which prompted blood lead concentration measurement (6.7umol/L, normal range $<0.24 \mathrm{umol} / \mathrm{L}$ ) and subsequent diagnosis of lead toxicity.

The patient later admitted to daily inhalational recreational use of opium obtained from Iran. DMSA chelation therapy was administered orally for three weeks. Opium was ceased and withdrawal managed using titrated benzodiazepines. Following chelation, blood lead concentration was $2.65 \mathrm{umol} / \mathrm{L}$, with complete symptom resolution.

2. A 43-year-old Iranian male presented to the ED with worsening abdominal pain, constipation and anorexia. Previous presentations to medical practitioners with abdominal pain had not revealed an obvious cause. FBE revealed a mild microcytic anaemia (Hb 110g/L). LFTs were slightly abnormal (Bilirubin 39umol/L, ALT 63U/L, AST 48U/L, GGT 165U/L). A blood film revealed Pappenheimer bodies and basophilic 
stippling. The patient reported his brother's recent presentation with similar symptoms following opium use (32-year old male described previously), and his subsequent diagnosis of lead poisoning. The patient admitted he was also ingesting opium obtained from Iran daily. Blood lead concentration was 7.75umol/L.

DMSA chelation therapy was administered for three weeks. Opioid withdrawal was managed using benzodiazepines and buprenorphine/naloxone (Suboxone). The patient did not attend follow-up reviews and therefore post-chelation therapy blood lead concentration was not measured.

3. A 36-year-old Iranian male was referred to the ED by his general practitioner with abdominal pain and lethargy. FBE revealed microcytic hypochromic anaemia ( $\mathrm{Hb}$ 76g/L). The blood film exhibited pronounced coarse basophilic stippling. Iron and vitamin B12 concentrations and were normal. Blood lead concentration was elevated (4.77umol/L). Renal and hepatic dysfunction were evident (creatinine 130umol/L eGFR 61, bilirubin 24umol/L, ALT 198U/L, AST 86U/L, ALP 115U/L and GGT 147U/L). Upon further questioning the patient acknowledged daily recreational ingestion of opium, reportedly obtained from Iran.

DMSA chelation therapy was administered for three weeks. Opium was ceased and withdrawal managed using methadone. Following chelation, blood lead concentration was $3.32 \mathrm{umol} / \mathrm{L}$ with marked improvement in symptoms and normalization of biochemistry.

4. A 22-year-old Iranian male presented to the ED with abdominal pain, constipation and per rectal bleeding during defecation. Full blood examination revealed microcytic 
hypochromic anaemia $(101 \mathrm{~g} / \mathrm{L})$. The blood film was initially reported with nonspecific changes. Iron stores were replete. CT abdomen/pelvis revealed large bowel distension without obstruction. A rigid sigmoidoscopy was performed to investigate per rectal bleeding which was unremarkable. An initial working diagnosis of inflammatory bowel disease was suggested given the constitution of symptoms. However, in light of a local Department of Health warning regarding opium-related lead poisoning, the blood film was repeated. Coarse basophilic stippling was identified on review and a blood lead concentration of 4.81umol/L confirmed lead poisoning. The patient then acknowledged daily ingestion and inhalation of recreational opium, allegedly originating from Iran.

DMSA chelation therapy was administered for three weeks. Opium was ceased and withdrawal managed using Suboxone. The patient did not attend further follow-up and therefore post-chelation therapy blood lead concentration was not measured.

All patients reported ingesting the opium as a sticky black paste, generally while alone. The source of opium was reported as a 'contact' within the local community. Although one patient (Patient 2) reported insomnia, no other lead related neurological toxicity was evident in any of the patients.

Health Department notification of raised blood lead concentrations is mandatory in Victoria. Recognition of this cluster of patients led to direct discussion with the Victorian Department of Health and issuance of a health alert within a week of the third patient's presentation.

\section{Discussion}

This article is protected by copyright. All rights reserved. 
Opium has been used as psychoactive drug for more than 5000 years. ${ }^{1}$ The isolation of morphine from poppy in 1804 led to the discovery of more potent opioids such as heroin, but in countries such as Afghanistan and the Islamic Republic of Iran opium remains a readily available alternative to more potent opioids. ${ }^{2}$

Opium use outside of the Middle East is less common. Recreational opioid users in Australia obtain heroin from supply routes originating from South East Asia (Myanmar, Thailand and Laos), and more recently from South-West Asia (Afghanistan, the Islamic Republic of Iran and Pakistan). ${ }^{3}$ Pharmaceutical opioids have also become a recent source of recreational opioid use in Australia. ${ }^{4}$

In this series of patients, recent immigration and maintenance of close contact with the Islamic Republic of Iran resulted in direct import and recreational use of an opioid through a less commonly recognised supply route. According to the 2017 World Drug Report, the Islamic Republic of Iran accounted for the greatest proportion of opiates seized in 2015 (49\% of seizures). ${ }^{5} \mathrm{~A}$ recent report highlighted smuggling of lead-contaminated opium via packets concealed in the gastrointestinal tract. ${ }^{6}$

Opium is harvested from ripening poppy seeds repeatedly incised over a period of 3-4 days. The sticky brown opium residue is typically collected the next morning after the seed 'tears'. Lead is not part of the opium production process, but may be added to increase weight or improve appearance. Addition of lead may also occur secondary to contamination from soil or equipment used during production. ${ }^{6}$ Lead-adulterated opium has been a public health issue in the Middle East since 2004. Opium can be heated and the fumes inhaled, however the most common route of exposure is ingestion (Figure 1). Lead within adulterated opium 
preparations is most effectively absorbed via the gastrointestinal tract. In the Islamic Republic of Iran, opium is the most commonly abused illicit drug, with an estimated prevalence of opium addiction of more than $2 \%$ of the population in $2015 .^{2}$ Of those individuals using opium in the Islamic Republic of Iran, more than 13\% were treated for lead poisoning in 20162017.

The effects of lead toxicity are wide-ranging and non-specific, making diagnosis challenging. ${ }^{7}$ This is further complicated when the lead toxicity originates from contaminated opium as a number of symptoms are similar to those observed with chronic opioid use. Common symptoms of lead toxicity include fatigue, anorexia and nausea with mild toxicity through to abdominal pain, renal impairment, encephalopathy and seizures in severe toxicity. Long-term adverse health effects associated with an increased body burden of lead include cognitive decline, renal disease, cataract formation and cardiovascular disease including hypertension. ${ }^{13}$ Untreated lead poisoning can prove fatal. ${ }^{8,9}$

Abdominal pain and constipation are common presenting complaints in previously reported cases of lead poisoning associated with contaminated opium. ${ }^{9-11}$ Constipation further compounds toxicity via reduced gut motility and increased absorption of lead in the gastrointestinal tract. The pathophysiological process leading to abdominal pain in lead poisoning is poorly understood. Postulated theories include spasmodic smooth muscle contraction, impaired luminal ion transport and altered gastrointestinal tract motility. Due to the rarity of lead poisoning, it is perhaps unsurprising that published cases demonstrate that patients often present multiple times with abdominal pain and undergo extensive 
investigations including pathology, radiology (including CT scans) and diagnostic laparoscopy or laparotomy before the diagnosis of lead poisoning is made. ${ }^{11}$

Microcytic hypochromic anaemia is noted in the majority of patients with acute lead toxicity as lead inhibits heme synthesis. ${ }^{8}$ Basophilic stippling on blood film is another classic finding. ${ }^{12}$ However, this is a less specific sign due to its association with other haematological and rheumatological conditions.

Lead toxicity is easily confirmed by measuring blood lead concentration. Once the diagnosis has been made, the cornerstone of management is removal from the source of lead. Chelation therapy with DMSA can be considered in symptomatic patients with significantly raised blood lead concentration. An exposed oxygen and sulphur atom within the DMSA molecule effectively bind lead, facilitating elimination through the renal tract. However, a course of DMSA only removes $1-2 \%$ of total body lead burden and therefore DMSA administration is reserved for patients with very high blood lead concentrations or patients with raised blood lead concentrations and significant clinical toxicity. Thresholds for chelation based solely on blood lead concentration are lower for patients at higher risk of toxicity including children and pregnant women. ${ }^{14}$

In patients where the source of lead toxicity is lead-adulterated opium, removal from the source is likely to result in an associated opioid withdrawal syndrome. Without treatment, opioid withdrawal symptoms are expected to resolve by 14 days, but strong periodic cravings can continue for months. To prevent relapse and therefore potential recurrence of lead toxicity, opioid replacement therapies should be offered. 
These recent cases highlight the potential for novel sources of lead toxicity in the Australian context. Clinicians should be mindful of patients presenting with persistent abdominal pain or non-specific symptoms, especially in those with a history of opium use. When lead poisoning is being considered, an FBE with blood film should be undertaken to assess for microcytic anaemia or basophilic stippling, with confirmatory diagnosis via elevated blood lead concentration. In those that have confirmed toxicity, removal from the source plus chelation and opioid replacement therapy should be considered in consultation with the appropriate services. Clinical follow-up with repeat blood lead concentration should be considered to ensure resolution of clinical toxicity. 


\section{References:}

1. Merlin MD. Archaeological evidence for the tradition of psychoactive plant use in the old world. Economic Botany. 2003;57(3):295-323.

2. Ghane T, Zamani N, Hassanian-Moghaddam H, Beyrami A, Noroozi A. Lead poisoning outbreak among opium users in the Islamic Republic of Iran, 2016-2017. Bulletin of the World Health Organization. 2018;96(3):165.

3. Morrison S. Researching heroin supply. Trends \& Issues in Crime and Criminal Justice. 2003(257):1.

4. The Royal Australasian College of Physicians. Prescription opioid policy: improving management of chronic non-malignant pain and prevention of problems associated with prescription opioid use. Sydney: 2009:5.

5. United Nations Office on Drugs and Crime (UNODC). Global overview of drug demand and supply: latest trends, cross-cutting issues [Internet]. UNODC Website: UNDOC; 2017 May [cited 2018 Jan 15]. Available from:

https://www.unodc.org/wdr2017/field/Booklet 2 HEALTH.pdf

This article is protected by copyright. All rights reserved. 
6. Zamani N, Hassanian-Moghaddam H. Ingestion of Lead-Contaminated Packs of Opium. New England Journal of Medicine. 2018;379(19):1861.

7. Barber T, Jacyna M. Acute lead intoxication from medications purchased online presenting with recurrent abdominal pain and encephalopathy. Journal of the Royal Society of Medicine. 2011;104(3):120-3.

8. Shiri R, Ansari M, Ranta M, Falah-Hassani K. Lead poisoning and recurrent abdominal pain. Industrial health. 2007;45(3):494-6.

9. Shojaeepour S, Fazeli M, Oghabian Z, Pourgholi L, Mandegary A. Oxidative stress in opium users after using lead-adulterated opium: The role of genetic polymorphism. Food and Chemical Toxicology. 2018;120:571-7.

10. Sadeghi A, Soleimani H, Nasseri-Moghadam S, Radmard AR. Lead contaminated opium as unusual cause of abdominal pain-case series. Iranian Journal of Radiology. 2017(5).

11. Soltaninejad K, Shadnia S. Lead poisoning in opium abuser in Iran: A systematic review. International journal of preventive medicine. 2018;9.

12. Valentine WN, Paglia D, Fink K, Madokoro G. Lead poisoning: association with hemolytic anemia, basophilic stippling, erythrocyte pyrimidine 5'-nucleotidase deficiency, and intraerythrocytic accumulation of pyrimidines. The Journal of clinical investigation. 1976;58(4):926-32.

13. Rosin A. The long-term consequences of exposure to lead. The Israel Medical Association Journal. 2009; 11(11):689-694. 
14. Austin Clinical Toxicology Guidelines

(http://www.austin.org.au/Assets/Files/Lead\%20Guideline SG[1].pdf ). Accessed $2^{\text {nd }}$ August 2019.

\section{Figure Legend}

Figure 1: Photograph of a lump of opium

Figure 2: Blood film with arrow demonstrating basophilic stippling

This article is protected by copyright. All rights reserved. 


\begin{abstract}
:
Lead poisoning is an uncommon and challenging diagnosis to make. In 2018, The Victorian Department of Health issued a health warning following four cases of lead poisoning associated with illicit opium use in Melbourne, Australia. We present these cases to highlight clinical features and the relevant investigations leading to diagnosis. All cases occurred in recent immigrants to Australia, who had access to non-traditional sources of opioids. Health care professionals should consider lead poisoning in patients with appropriate symptoms and a history of illicit opium use.
\end{abstract}




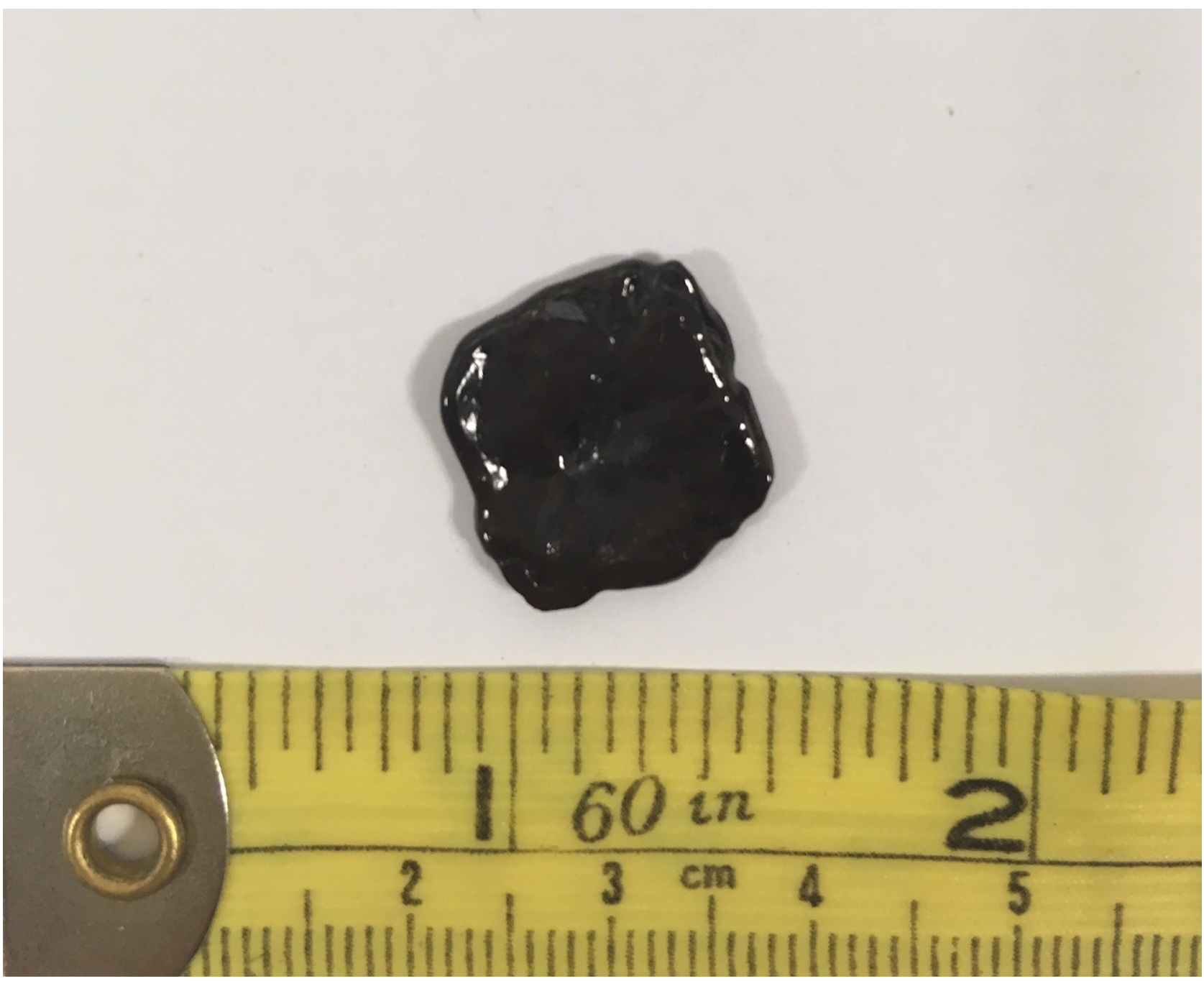

IMJ_14729_Figure 1.JPG

This article is protected by copyright. All rights reserved. 


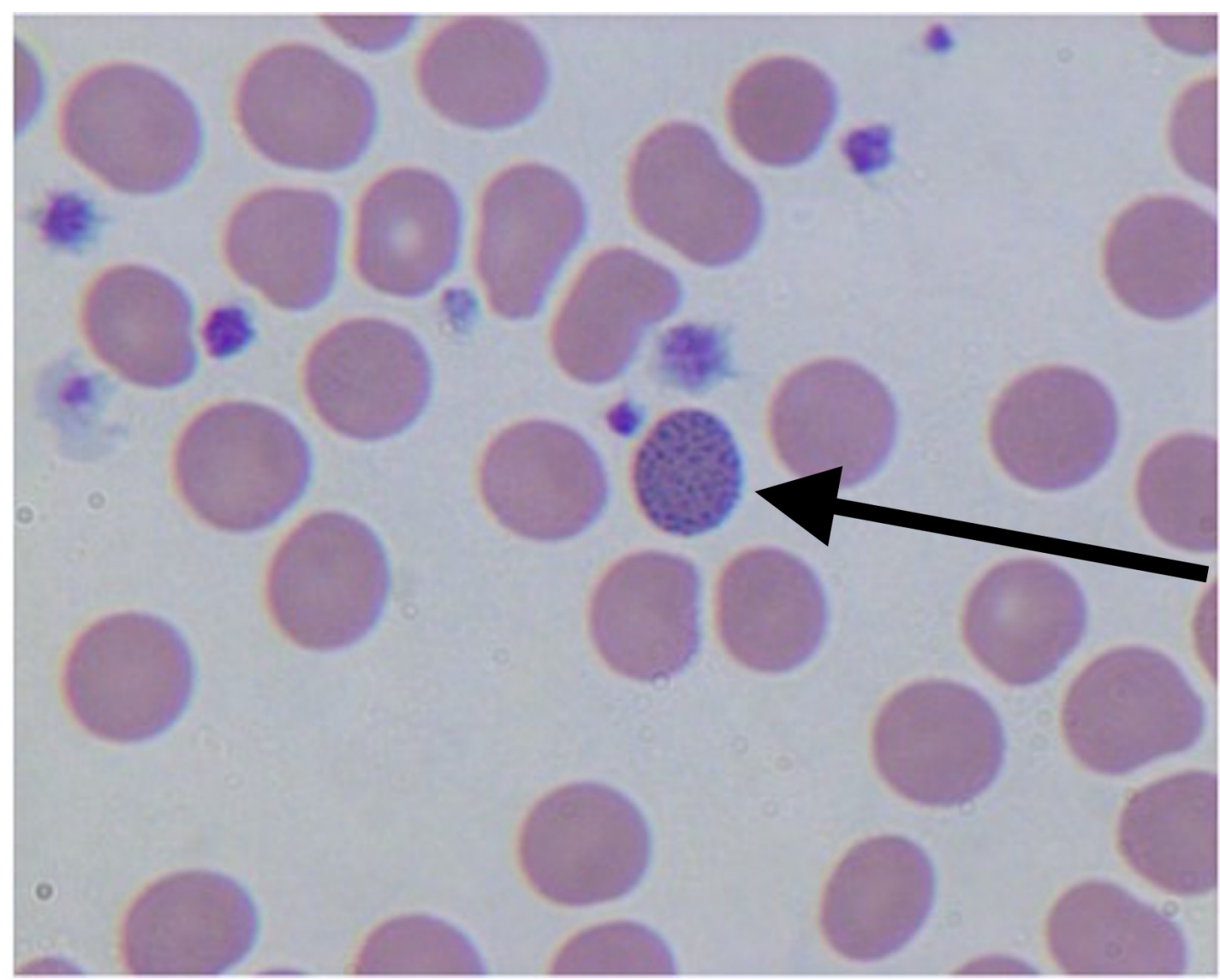

IMJ_14729_Figure 2.jpg

This article is protected by copyright. All rights reserved. 


\section{Case Series: Lead Poisoning Associated with Illicit Opium Use}

Joshua Wong ${ }^{1}$, Elyssia Bourke ${ }^{2}$, Vanessa Roberts ${ }^{3}$, Seok Ming Lim ${ }^{1}$, Douglas Johnson ${ }^{1}$ Peter Shane Hamblin ${ }^{3}$, Harin Karunajeewa ${ }^{3}$ and Shaun Greene ${ }^{2}$

${ }^{1}$ The Royal Melbourne Hospital, ${ }^{2}$ Austin Health and ${ }^{3}$ Western Health, Victoria, Australia

Authors Details:

\begin{tabular}{|c|c|c|c|}
\hline Author & Position & Affiliation & Contribution \\
\hline Dr Joshua Wong & $\begin{array}{c}\text { General Medical } \\
\text { Registrar }\end{array}$ & $\begin{array}{l}\text { The Royal } \\
\text { Melbourne Hospital }\end{array}$ & $\begin{array}{l}\text { Clinician taking care of } \\
\times 2 \text { of the cases in the } \\
\text { case series and co-writer } \\
\text { of the manuscript }\end{array}$ \\
\hline Dr Elyssia Bourke & Emergency Registrar & Austin Health & $\begin{array}{l}\text { Clinician taking care of } \\
\times 1 \text { of the cases in the } \\
\text { case series and co-writer } \\
\text { of the manuscript }\end{array}$ \\
\hline Dr Vanessa Roberts & Surgical Resident & Western Health & $\begin{array}{c}\text { Clinician taking care of } \\
\text { x1 of the cases, } \\
\text { contributed case to } \\
\text { manuscript }\end{array}$ \\
\hline Dr Seok Ming Lim & $\begin{array}{c}\text { Geriatrician } \\
\text { Medical Unit } 2 \\
\text { Consultant } \\
\text { Head of the Hospital in } \\
\text { The Home Unit }\end{array}$ & $\begin{array}{l}\text { The Royal } \\
\text { Melbourne Hospital }\end{array}$ & $\begin{array}{c}\text { Consultant taking care of } \\
\times 1 \text { of the cases and } \\
\text { editor of entire } \\
\text { manuscript }\end{array}$ \\
\hline A/Prof Douglas Johnson & $\begin{array}{c}\text { Infectious Diseases } \\
\text { Physician } \\
\text { General Medical Unit } \\
\text { Consultant } \\
\text { Head of General Medical } \\
\text { Department }\end{array}$ & $\begin{array}{l}\text { The Royal } \\
\text { Melbourne Hospital }\end{array}$ & $\begin{array}{c}\text { Editor of entire } \\
\text { manuscript }\end{array}$ \\
\hline $\begin{array}{c}\text { A/Prof Peter Shane } \\
\text { Hamblin }\end{array}$ & Endocrinologist & Western Health & $\begin{array}{c}\text { Supervisor for case } \\
\text { submitted by Western } \\
\text { Health, aided in editing } \\
\text { of the submitted case to } \\
\text { the case series }\end{array}$ \\
\hline
\end{tabular}




\begin{tabular}{|c|c|c|c|}
\hline $\begin{array}{c}\text { A/Prof Harin } \\
\text { Karunajeewa }\end{array}$ & $\begin{array}{c}\text { General Medicine } \\
\text { Consultant } \\
\text { Director Of Clinical } \\
\text { Research }\end{array}$ & Western Health & $\begin{array}{c}\text { Consultant taking care of } \\
\text { x1 of the cases }\end{array}$ \\
\hline Dr Shaun Greene & $\begin{array}{c}\text { Medical Toxicologist } \\
\text { Emergency Physician } \\
\text { Victorian Poisons } \\
\text { Information Centre }\end{array}$ & Austin Health & $\begin{array}{c}\text { Overall supervisor for } \\
\text { the case series and } \\
\text { editor of the entire } \\
\text { manuscript }\end{array}$ \\
\hline
\end{tabular}

\section{Correspondence:}

Joshua Wong, General Medical Office, The Royal Melbourne Hospital, Parkville, VIC, 3050, Australia. Mobile+61 433325 100. Email: joshua.wong@mh.org.au,

\section{Acknowledgements:}

Dr Ashish Kumar Panigrahi (Clinical Haematology Registrar, Peter MacCallum Cancer Centre) for providing the blood films included in Figure 1.

\section{Word Count:}

Abstract -85 words

Main Text -1713 words

\section{Abstract:}

Lead poisoning is an uncommon and challenging diagnosis to make. In 2018, The Victorian Department of Health issued a health warning following four cases of lead poisoning associated with illicit opium use in Melbourne, Australia. We present these cases to highlight clinical features and the relevant investigations leading to diagnosis. All cases occurred in recent immigrants to Australia, who had access to non-traditional sources of opioids. Health care professionals should consider lead poisoning in patients with appropriate symptoms and a history of illicit opium use.

\section{Key words:}

Lead Poisoning, Opium, Opioids, Iran, Australia 


\section{University Library}

\section{- M M N E R VA A gateway to Melbourne's research publications}

Minerva Access is the Institutional Repository of The University of Melbourne

Author/s:

Wong, J;Bourke, E;Roberts, V;Lim, SM;Johnson, D;Hamblin, PS;Karunajeewa, H;Greene, S

Title:

Lead poisoning associated with illicit opium use

Date:

2020-02-01

Citation:

Wong, J., Bourke, E., Roberts, V., Lim, S. M., Johnson, D., Hamblin, P. S., Karunajeewa, H. \& Greene, S. (2020). Lead poisoning associated with illicit opium use. INTERNAL MEDICINE JOURNAL, 50 (2), pp.239-242. https://doi.org/10.1111/imj.14729.

Persistent Link:

http://hdl.handle.net/11343/275354 